\title{
Valorization of spent coffee grounds as the specialty material for dullness and aging of skin treatments
}

Mayuree Kanlayavattanakul ${ }^{1,2^{*}}$ (]) Nattaya Lourith ${ }^{1,2}$ and Puxvadee Chaikul ${ }^{1,2}$

\begin{abstract}
Background: Coffee beans contain oil with health benefits from fatty acids. The unprocessed and processed coffee beans are mostly identical in coffee oil quality and are substantively supplied for certain industries. However, the costeffective valorization of specialty ingredients from spent coffee grounds for cosmetics is sparely presented. Linoleic acid-rich spent coffee oil, as a specialty material for skin lightening and antiaging cosmetics, is objectively to be presented.

Results: Spent coffee oils were prepared by different methods. The most cost-effective material with a high extraction yield, linoleic acid content and unsaturated/saturated fatty acid (UFA/SFA) ratio (13.21 $\pm 0.25,32.09 \%$ and 0.97$)$ was modified. The modified oil was boosted in linoleic acid ( $77.20 \%$ or $140.57 \%$ improvement) and the UFA/SFA ratio (33.12). The physicochemical properties of the oil were applicable for cosmetics as per its safety profiles in B16F10 melanoma and normal human skin fibroblast cells. The oil significantly better inhibited cellular melanogenesis than kojic and linoleic acids $(p<0.01$ ), with prominent tyrosinase and TRP-2 inhibitions. The cellular antioxidant activity of the oil was comparable to those of ascorbic and linoleic acids. The collagen stimulating efficacy of the oil was significantly better than that of ascorbic but comparable to that of linoleic acid as indicated by the MMP-2 inhibitory activities ( $p<0.01$ and $p<0.001$, respectively).

Conclusions: The oil is a specialty material for skin brightening and skin wrinkle reduction/skin elasticity improvement products. A successive circular bioeconomy of spent coffee ground waste in a more profitable cosmetic industry is indicated.
\end{abstract}

Keywords: Spent coffee grounds, Fatty acids, Cosmetics, Cellular biological activity, Specialty material, Biological residues

\section{Background}

Coffee is an important industrial crop worldwide, and the global demand continues to increase every year in all forms, i.e., coffee beans and processed coffee. Thailand is one of the major coffee producers and ranks as the global no. 7 exporter of processed coffee [1]. Accordingly, there are many agricultural residues, especially spent coffee

\footnotetext{
*Correspondence: mayuree@mfu.ac.th

1 School of Cosmetic Science, Mae Fah Luang University, Chiang

Rai 57100, Thailand

Full list of author information is available at the end of the article
}

grounds (SCG) wasted from the instant coffee industry. This is a challenge for recovering specialty material for certain industries $[2,3]$.

The bean of coffee contains $10-12 \%$ oil, which is composed of fatty acids important for skin and hair esthetic conditions [4-6], i.e., linoleic (44\%), palmitic (34), oleic (9) and stearic (7\%) acids. The unprocessed and processed coffee beans are mostly identical in coffee oil quality and are substantively supplied for certain industries [7]. Several attempts have been conducted to isolate valuable materials from SCG [8], especially in biofuel applications [9]. The key concepts of a circular bioeconomy 
are recycling resources into the form of multiple products with the feasibility of scale-up integration with costeffective processes, more profit and market demand for the transformed product [10]. Cosmetics is a potential sector in accordance with consumers' awareness and preference for sustainable or natural products [11], particularly the niche market.

In the present study, SCG wasted from the instant coffee industry were therefore objectively valorized as a specialty material for skin brightening and antiaging cosmetics using a cost-effective and industrially feasible method. Data required for the cosmetic industry [12], i.e., physicochemical, chemical and biological profiles of the coffee oil, are presented. Derivatization of coffee products for new industry uses, i.e., value-added cosmetic products, positively impacts the value chain of coffee and fits consumers' awareness and expectations of sustainable/natural cosmetics.

\section{Methods}

\section{Materials}

All reagents and chemicals used for extractions were of commercial grade. Those for in vitro and cell culture assays were analytical grade, unless otherwise stated. Standards and solvents for GC/MS analysis were GC grade.

\section{Preparation of SCG oils}

SCG were given from the ready-to-drink coffee factory (Chachoengsao, Thailand). SCG were air-dried under the shade, oven-dried at $45{ }^{\circ} \mathrm{C}$ and kept in a vacuumsealed package. The dried SCG were activated with heat, extracted with $n$-hexane at the solid/solvent $(\mathrm{w} / \mathrm{v})$ ratio of $1: 7.5[13,14]$ for 1 and $3 \mathrm{~h}$ by different conditions, i.e., maceration at $60{ }^{\circ} \mathrm{C}\left(60{ }^{\circ} \mathrm{C} \_1 \mathrm{~h}\right.$ and $\left.60{ }^{\circ} \mathrm{C} \_3 \mathrm{~h}\right)$, Soxhlet (Sox_1h and Sox_3h), reflux (Ref_1h and Ref_3h) and maceration under ambient condition (RT_1h and RT_3h). The extraction procedure of each condition was undertaken in triplicates, and the extraction yields were compared.

\section{Fatty acid profiles of SCG oils}

SCG oil (8 samples) was esterified by mixing the oil with toluene, $\mathrm{MeOH}$, and $8 \% \mathrm{HCl}$, and incubated at $45^{\circ} \mathrm{C}$ for $24 \mathrm{~h}$. The resulting reacted solution was partitioned with $n$-hexane, the organic phase was dried over $\mathrm{MgSO}_{4}$ anhydrous and filtered to collect the FAMEs solution for $\mathrm{GC} /$ MS analysis. The FAMEs solution $(1 \mu \mathrm{L})$ was injected $\left(220^{\circ} \mathrm{C}\right)$ in the splitless mode into a gas chromatography (Agilent, $6890 \mathrm{~N}$, USA). Chromatographic separation was by a HP-5MS capillary column (Agilent, $30 \mathrm{~m} \times 250 \mu \mathrm{m}$, $0.25 \mu \mathrm{m}$ film thickness) with the oven program starting at $50{ }^{\circ} \mathrm{C}(5 \mathrm{~min})$, rising to $65{ }^{\circ} \mathrm{C}$ at a rate of $2{ }^{\circ} \mathrm{C} / \mathrm{min}$, and then $200{ }^{\circ} \mathrm{C}\left(5{ }^{\circ} \mathrm{C} / \mathrm{min}, 5 \mathrm{~min}\right)$, and $250{ }^{\circ} \mathrm{C}\left(10{ }^{\circ} \mathrm{C} /\right.$ min) and held for $10 \mathrm{~min}$, at which the carrier gas was helium $(1.0 \mathrm{~mL} / \mathrm{min})$. Mass spectrophotometer (Agilent, $5973 \mathrm{~N}$ ) and the reference mass spectrum (MSWilley7n.1database) were analyzed [13, 14].

\section{Preparation of linoleic acid-rich SCG oil}

SCG oil was modified by different methods to archive linoleic acid content, i.e., crystallization [15] and complexation [16]. The modified oils were comparatively assessed on their fatty acid profiles as above.

\section{Physicochemical properties of SCG oils}

The acid, iodine, peroxide, saponification, and unsaponification values were determined in accordance with the official methods [17].

\section{Cellular activity assessments in B16F10 melanoma cells} B16F10 melanoma cells (ATCC ${ }^{\circledR}$ CRL 6475, USA) used in this study were cultured in DMEM supplemented with $10 \% \mathrm{FBS}$ and $1 \%$ penicillin/streptomycin at $37^{\circ} \mathrm{C}$ in a humidified incubator with $5 \% \mathrm{CO}_{2}$. The cells that were grown to semiconfluence, were harvested by $0.25 \%$, w/v trypsin and $0.06 \mathrm{mM}$ EDTA in phosphate buffer saline [18].

\section{Cellular safety assessment}

The sulforhodamine B (SRB) assay was assessed for cell cytotoxicity. Cells $\left(1 \times 10^{4}\right.$ cells/well $)$ in 96-well plate were treated with different concentrations of the samples for $72 \mathrm{~h}$. The adherent cells were fixed, washed, dyed and absorbance measured at $540 \mathrm{~nm}$ with the microplate reader (SPECTROstar Nano, BMG Labtech). The cell viability was compared with the control treated with absolute ethanol [18].

\section{Activity on melanin production}

Cells with a same density with cytotoxicity assay were plated in a 6-well plate and incubated for $24 \mathrm{~h}$. Samples and absolute ethanol were separately added and incubated for more $72 \mathrm{~h}$ under the same condition. Melanin content was measured at $450 \mathrm{~nm}$ in parallel with total protein content analysis. The relative ratio of melanin content (\%) was calculated $[18,19]$.

\section{Inhibitory effect against tyrosinase}

Cells $\left(5 \times 10^{5}\right.$ cells/well) in 6 -well plate was incubated for $24 \mathrm{~h}$, treated with the samples and incubated for more $72 \mathrm{~h}$. The treated cells were washed, lysed with RIPA buffer containing protease inhibitor, incubated $\left(4{ }^{\circ} \mathrm{C}, 30 \mathrm{~min}\right)$ and centrifuged $(14,000 \times g, 10 \mathrm{~min})$. The supernatants were mixed with $0.05 \% \mathrm{~L}-\mathrm{DOPA}$ in $50 \mathrm{mM}$ phosphate buffer ( $\mathrm{pH}$ 6.8) and incubated for $2 \mathrm{~h}$ at 
$37{ }^{\circ} \mathrm{C}$. Tyrosinase activity was determined by means of DOPAchrome formation at $490 \mathrm{~nm}$. The enzyme activity was compared with the standard mushroom tyrosinase. The relative ratio of the enzyme activity (\%) was calculated [18].

Inhibitory effect against tyrosinase-related proteins-2 (TRP-2) The supernatant of the lysis treated cells was mixed with $1 \mathrm{mM}$ phenylthiourea, $2 \mathrm{mM}$ EDTA and $10 \mathrm{mM}$ sodium phosphate buffer ( $\mathrm{pH}$ 6.8). Thereafter, the mixture was added with DOPAchrome containing $1 \mathrm{mM}$ L-DOPA and $2 \mathrm{mM} \mathrm{NaIO}$, and incubated at $37{ }^{\circ} \mathrm{C}$ for $2 \mathrm{~h}$. The reduction of DOPAchrome was measured at $490 \mathrm{~nm}$. The reaction mixture with bovine serum albumin instead of the cell supernatant was used as a negative control. The TRP-2 activity was compared with the control and expressed as the relative ratio (\%) [18].

\section{Cellular activity assessments in human skin fibroblasts}

Normal human skin fibroblasts or NHF ATCC $^{\circledR}$ CRL 2097, USA), primary cell culture passage at 10-20th passage, cultured in $75-\mathrm{cm}^{2}$ flask in DMEM medium supplemented with $10 \%$ FBS and $1 \%$ penicillin/streptomycin at $37{ }^{\circ} \mathrm{C}$ under $5 \% \mathrm{CO}_{2}$, were used in this study. The cells were grown and harvested by $0.25 \% \mathrm{w} / \mathrm{v}$ trypsin and $0.06 \mathrm{mM}$ EDTA in phosphate buffer saline [20].

\section{Cellular safety assessment}

The SRB assay was used for cell cytotoxicity determination as above.

\section{Antioxidant activity assessment}

Incubation of the seeded NHF in 96-well plate $\left(1 \times 10^{4}\right.$ cells/well $)$ for $48 \mathrm{~h}$ was undertaken. Thereafter, the cells were treated with the samples as well as the solvents (absolute ethanol or culture medium) for $24 \mathrm{~h}$. Consequently, they were treated with the fresh medium containing $150 \mu \mathrm{M} \mathrm{H}_{2} \mathrm{O}_{2}$ and further incubated for $3 \mathrm{~h}$. The cells were fixed, washed, dyed with SRB, and solubilized with $10 \mathrm{mM}$ Tris base and monitored at $540 \mathrm{~nm}$ [20].

\section{Cellular collagen production activity}

NHF $\left(1 \times 10^{5}\right.$ cells/well $)$ in 12 -well plate cultured in the non-fetal bovine serum media for $24 \mathrm{~h}$ were treated with the samples and further incubated for $24 \mathrm{~h}$. Lysis buffer containing protease inhibitor was added, dyed with Sirius Red and further incubated under an ambient condition for $30 \mathrm{~min}$. Dyed cell pellets were collected by means of a centrifugation, and washed with $0.01 \mathrm{M} \mathrm{HCl}$. The cell pellets were dissolved in $0.01 \mathrm{M} \mathrm{NaOH}$. The collagen content was examined at $550 \mathrm{~nm}$ in addition to protein content (Bradford assay). The relative ratio of collagen production was calculated in a comparison with that of the control $[21,22]$.

\section{Inhibitory effect against matrix metalloproteinase-2 (MMP-2) assay}

NHF $\left(5 \times 10^{5}\right.$ cells/well $)$ in 6 -well plate, cultivated without the supplement of fetal bovine serum, were incubated for $24 \mathrm{~h}$. The cells were treated with the sample and incubated for $72 \mathrm{~h}$. The supernatant was collected, MMP-2 quantification was carried out by SDS-PAGE zymography using gelatin as the substrate. The inhibitory effect was calculated in a comparison with that of the control [20].

\section{Statistical analysis}

Data are presented as the mean \pm SD. The results from the cell cultures study are expressed as the mean \pm SEM. Statistical analysis was performed using the SPSS program version 16.0 for Windows. The parameters were compared and analyzed using one-sample $t$ test and ANOVA test (post hoc analysis) with a significance level of $p<0.05$.

\section{Results and discussion}

Recently, consumers' concerns about environmental and sustainable issues have dramatically increased with the awareness of integrating benefits for farmers producing the agricultural crops supplied for certain industries. Thus, valorization of industrial crops is not only an exhaustive issue among researchers, but also consumers and is widely regarded as a circular bioeconomy. The key concepts of a circular bioeconomy are recycling resources into the form of multiple products with the feasibility of scale-up integration with cost-effective processes, more profit and market demand for the transformed product [10]. Of these, cosmetics are exhibited as the appointed sector. Coffee, the no. 1 global favorite beverage, is highlighted as a potential industrial crop to be explored for its sustainable utilization, which is beneficial for its value chain. In particular, for SCG due to the huge portion left over as wasted from instant coffee factories, retail industries, and private coffee shops, it is worth revealing its circular bioeconomy [2,3]. Although there have been attempts to evaluate SCG, biofuels have been shown to be the major application $[8,9]$. Personal care and cosmetic products with more profit with high market demand are sparsely presented [23].

Coffee oil (10-12\%) is composed of fatty acids, such as linoleic, palmitic, oleic and stearic acids (44, 34, 9 and $7 \%$ ), which are useable for certain industries, including cosmetics. In addition, the quality of the processed and unprocessed coffee oil is similar [7]. High natural 


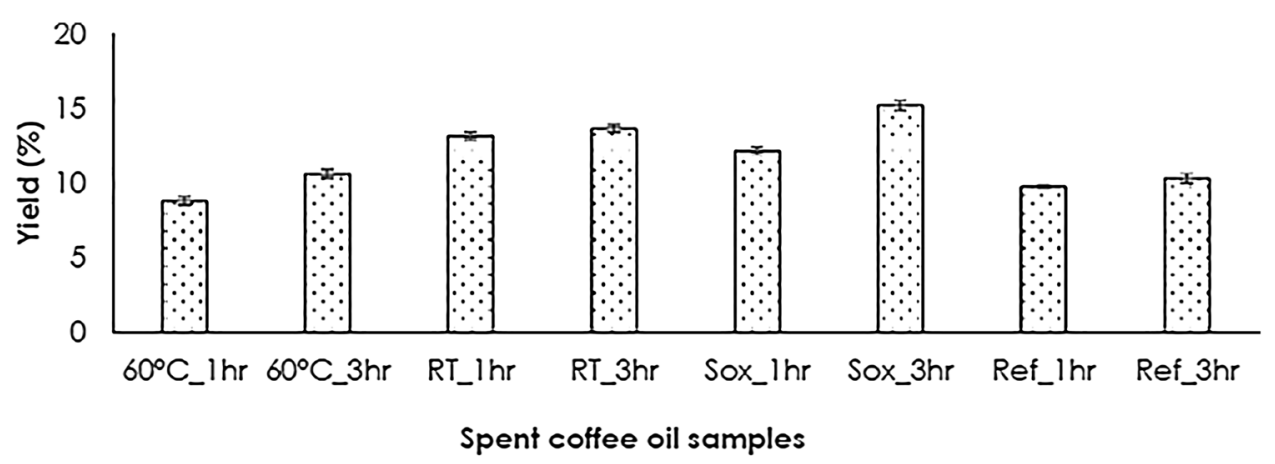

(A)

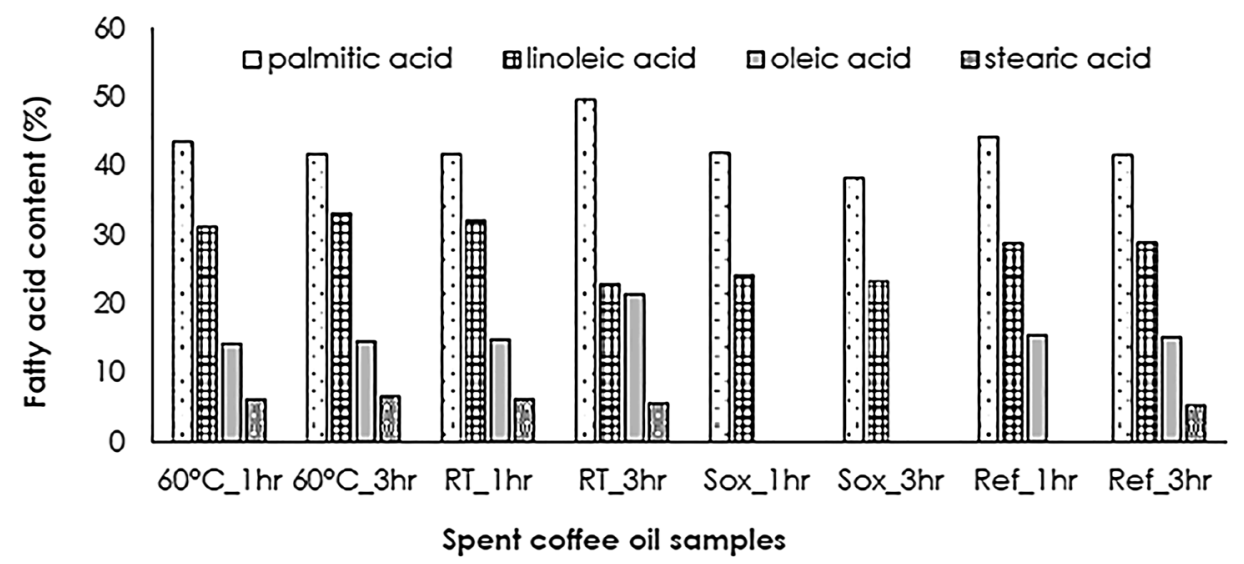

(B)

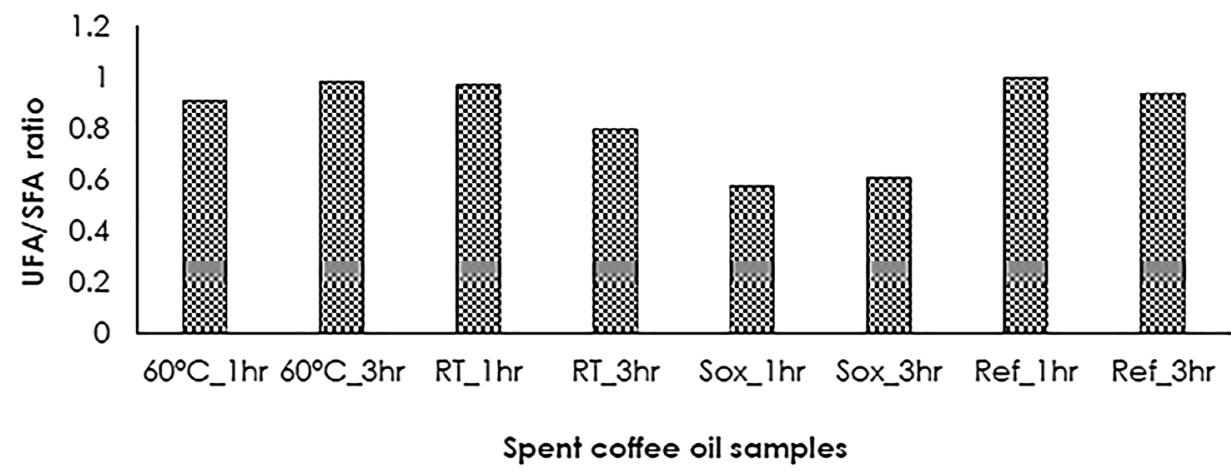

(C)

Fig. 1 Extraction yield (a), fatty acid profiles (b), and UFA/SFA ratio (c) of SCG oils prepared by different conditions

cosmetic demand includes plant oils products [24]. The preparation of SCG oil for cosmetic uses is therefore a challenge.

\section{Preparation and fatty acid profiles of SCG oils}

SCG oil colors were in harmony with those of the reported oil, i.e., dark-orange to brownish-chocolate [25]. $n$-Hexane was used as the extractive solvent based on its use as the major and feasible solvent for industrial vegetable oil production [13, 14, 26]. Each extraction condition was conducted at the same SCG per solvent ratio that was not less than 1:7 to maximize the extraction yield [27].

SCG oils prepared by different methods were comparable in extraction yields (< $10 \%$ differences), as shown in Fig. 1a. The oil contents extracted were in accordance with the previously reported $10-12 \%$ oil content of coffee [7]. Thus, maceration without heat for 1 and $3 \mathrm{~h}$ was 
shown to be promising, cost-effective and easy-to-scale method [10] for SCG oil preparation. All SCG oils were thereafter comparatively assessed bases on their fatty acid profiles (Fig. 1b).

The oils mainly contained palmitic (38-49\%), followed by linoleic (22-33\%), oleic (14-21\%) and stearic (5-6\%) acids, which were in accordance with the coffee oil prepared by supercritical $\mathrm{CO}_{2}$ [28] extraction. It should be noted that maceration afforded a higher proportion of linoleic acid than Soxhlet and reflux. Moreover, the UFA/ SFA ratio of SCG oils ranged between 0.5 and 1 (Fig. 1c). In addition, the revealed content of linoleic acid in SCG oil was greater than those reported in the oils of para rubber and tea seeds $[29,30]$.

Natural extracts with high UFA contents are more beneficial for health [31]. Linoleic and oleic acids are important UFAs for cosmetics [4-6]. Of these, the potency of linoleic acid against melanogenesis is superior to that of oleic acid. In contrast, palmitic and stearic acids exacerbate melanogenesis [29, 30]. SCG oils containing these cosmetically important fatty acids are therefore appointed for different cosmetic claims. Taken into account the high demand for skin brightening products, SCG oil with a high content of linoleic acid would be a more feasible fit for the market, especially in Asian countries.

The RT_1hr sample with a high yield, linoleic acid content and UFA/SFA ratio $(13.21 \pm 0.25 \%, 32.09 \%$ and 0.97) was selected for further modification on the basis of the oil quality and feasibility. This extraction is the lowest cost method that should be more feasible for scaling-up [10] in industrial production [32].

\section{Preparation of linoleic acid-rich SCG oil}

The selected SCG oil was modified in an attempt to enhance the linoleic acid quantity. The oil was first modified on the basis of crystallization [15, 33, 34]. The frozen oil was centrifuged to separate the supernatant and crystal (F_L and F_S), which were comparatively quantified based on their fatty acid profiles in a comparison with the original unmodified sample (RT_1hr; Fig. 2). However, the linoleic acid content was almost identical to that of the RT_1hr sample with regards to the UFA/SFA ratio.

Complexation, which is the industrial method for preparing highly unsaturated fatty acids supplied for food products $[16,35,36]$, was thereafter used to modify the oil. This method was conducted at a ratio of SCG oil:urea:ethanol $(\mathrm{w} / \mathrm{w} / \mathrm{v})$ of 1:2.5:50 [16] to give a $\mathrm{C} 1$ sample. Linoleic acid was increased to $53.24 \%$ or $65.9 \%$ enhancement from the unmodified oil with an improvement of the UFA/SAF ratio to 9.20. Complexation was further modified from the literature methods [16, 35, 36] (data not shown) to give linoleic acid-rich SCG oil
(LA-SCG) containing $77.20 \%$ linoleic acid (140.57\% improvement) with an induction of UFA/SFA ratio (33.12). LA-SCG oil was therefore assessed for its physicochemical properties.

\section{Physicochemical properties of SCG oils}

SCG oils physicochemically fall in the applicable range for cosmetics [13, 14]. LA-SCG oil was shown to have lower acid, peroxide and unsaponification values than the original unmodified oil (Table 1), indicating a lower risk of oxidation or hydrogenation of the modified oil. In other words, LA-SCG oil should be more stable than SCG oil. The higher iodine and saponification values of the modified oil correspond with fatty acid profiles consisting of high molecular weight fatty acids, i.e., linoleic and oleic acids. These SCG oils were therefore comparatively assessed for their safety and activity in cell cultures.

\section{Safety and activity in B16F10 melanoma Safety assessment}

SCG oils were safety examined in B16F10 melanoma first before the cellular antimelanogenesis study. In addition, SCG oil fatty acids were assessed in parallel. The test samples were shown to be safe toward the cells in a concentration range of $0.1-10 \mu \mathrm{g} / \mathrm{mL}$ with a cell viability of more than $80 \%$ (Fig. 3a). The inhibitory concentration at $50 \%\left(\mathrm{IC}_{50}\right)$ values against the cells were calculated and shown to be 0.0915 and $0.0906 \mathrm{mg} / \mathrm{mL}$ for SCG oil and LA-SCG oil and 0.1675, 0.1709, 0.2051 and $0.1486 \mathrm{mg} /$ $\mathrm{mL}$ for palmitic, linoleic, oleic and stearic acids, respectively. The cytotoxic doses of SCG oils were obviously lower than those of the standard fatty acids. These might be ruled by the variety of fatty acids in the oil, which is common in the case of plant oil [29]. The antimelanogenesis of SCG oils was thereafter examined at the highest safe concentration, $0.01 \mathrm{mg} / \mathrm{mL}$, in comparison with the standards.

\section{Antimelanogenesis assessment}

Theophylline activates melanin production via the cyclic adenosine monophosphate (cAMP) pathway with an induction ability on dopa- and gamma-glutamyltranspeptidase-reactive cells [37]. Kojic acid actively suppresses melanin production by chelating with a metal center of the dicopper catalyst of tyrosinase [38]. They were used as the positive and negative controls in this study accordingly.

Theophylline clearly induced melanogenesis as per stearic and palmitic acids, in contrast with the standards kojic, linoleic and oleic acids and SCG oils. LA-SCG oil remarkably suppressed cellular melanin production (Fig. 3b). Its activity was significantly better than those of kojic, linoleic and oleic acids $(p<0.01)$. SCG oil was able 


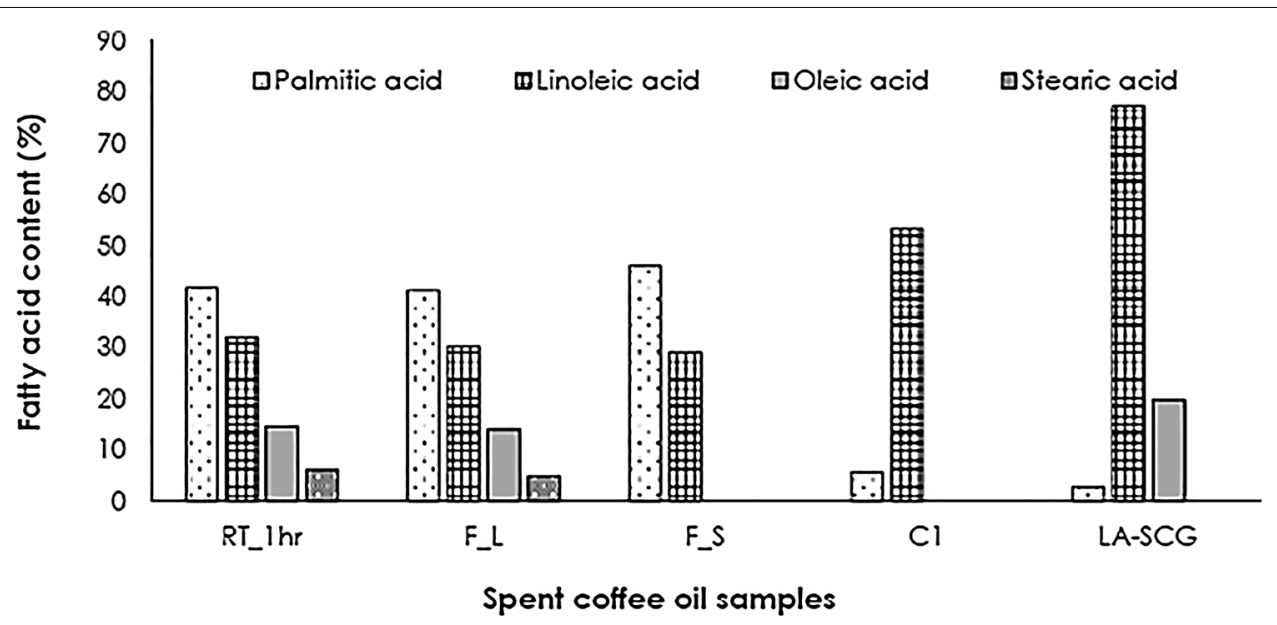

(A)

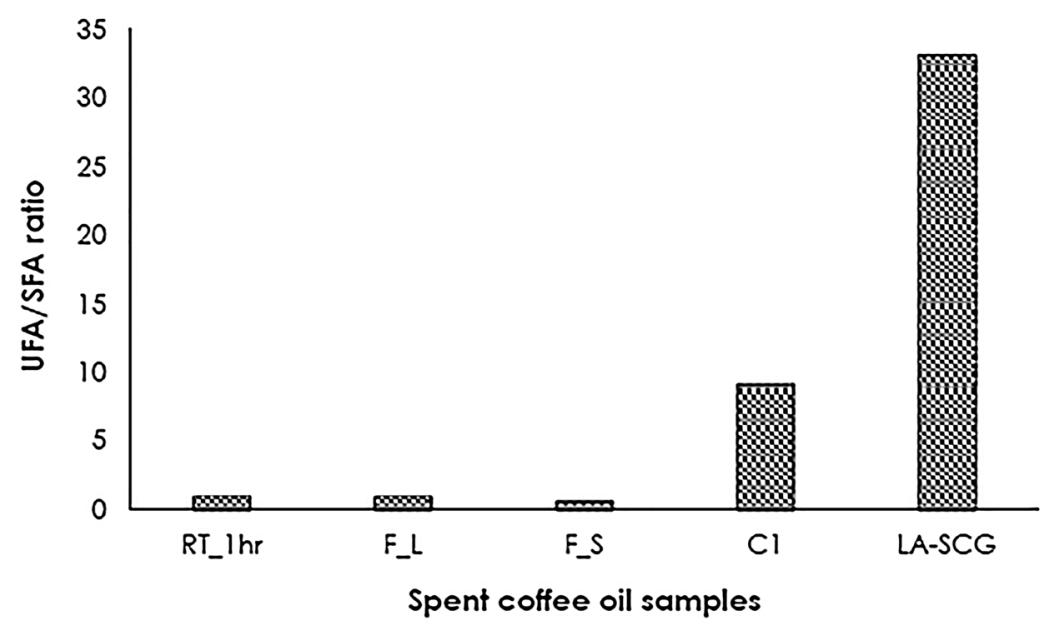

(B)

Fig. 2 Fatty acid profiles (a) and UFA/SFA ratio (b) of the modified SCG oils

Table 1 Physicochemical properties of SCG and LA-SCG oils

\begin{tabular}{llrrrr}
\hline SCG oil & \multicolumn{5}{l}{ Physicochemical property } \\
\cline { 2 - 6 } & AV & IV & PV & SV & USV \\
\hline RT_1hr & $201.14 \pm 1.07$ & $7.32 \pm 0.12$ & $113.80 \pm 0.67$ & $0.86 \pm 0.02$ & $16.24 \pm 0.85$ \\
LA-SCG & $164.32 \pm 1.12$ & $9.59 \pm 0.08$ & $64.23 \pm 1.51$ & $0.96 \pm 0.02$ & $7.48 \pm 0.06$ \\
\hline
\end{tabular}

$A V$ acid value; $I V$ iodine value; $P V$ peroxide value; $S V$ saponification value; USV unsaponification value

to inhibit cellular melanin production but insignificantly differed from the standard inhibitors $(p>0.05)$.

The antimelanogenesis of SCG oils was obviously related to UFAs, i.e., linoleic and oleic acids. These fatty acids were reported to diminish UV-induced melanin production in cell culture and animal models. Melanin production in melanocytes was reduced with an escalating ability for tyrosinase denaturation [31, 39, 40]. Actions of these SCG oils on tyrosinase and TRP-2 were further evaluated. 


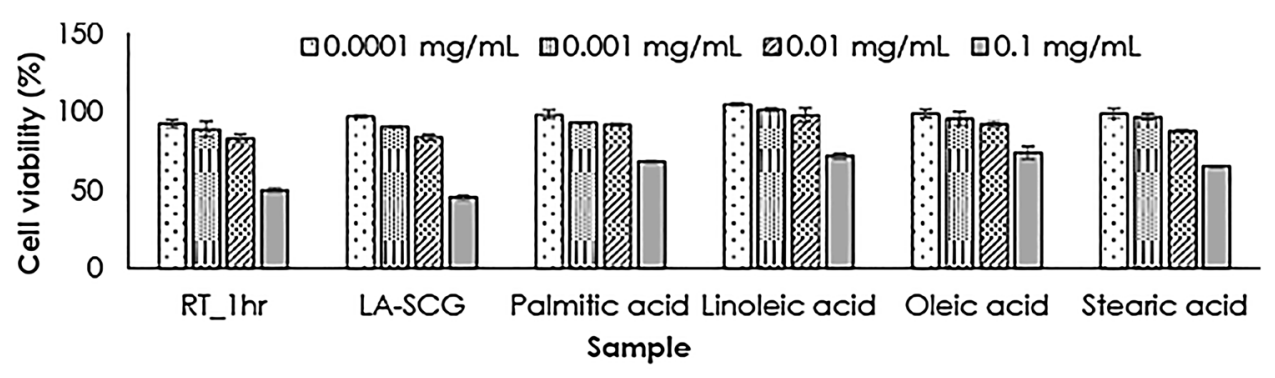

(A)

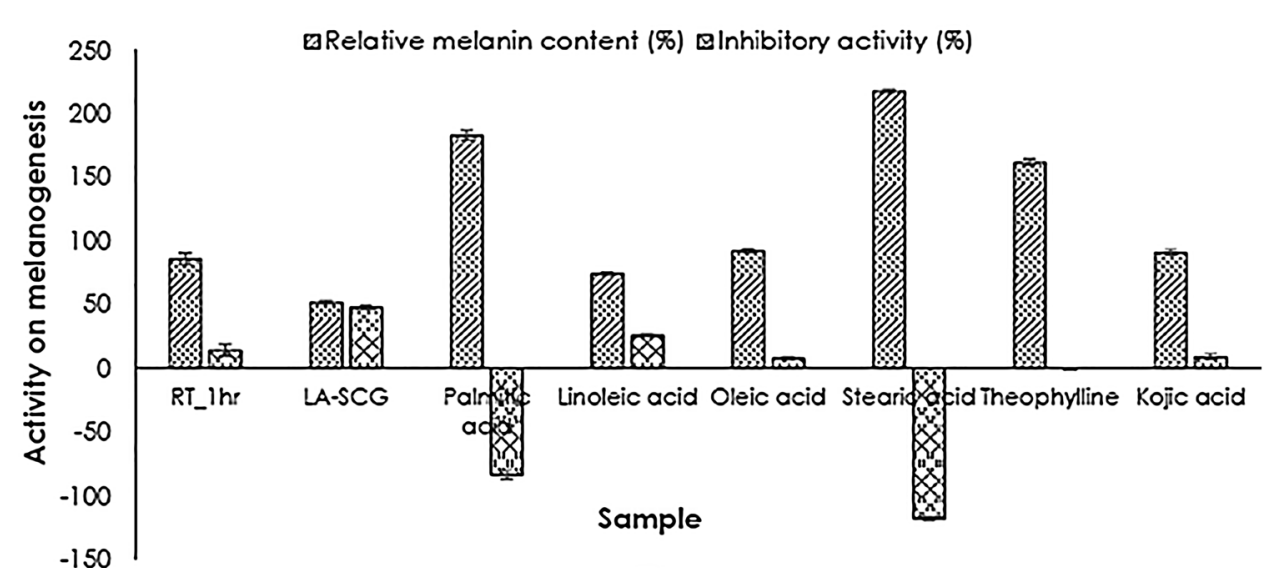

(B)

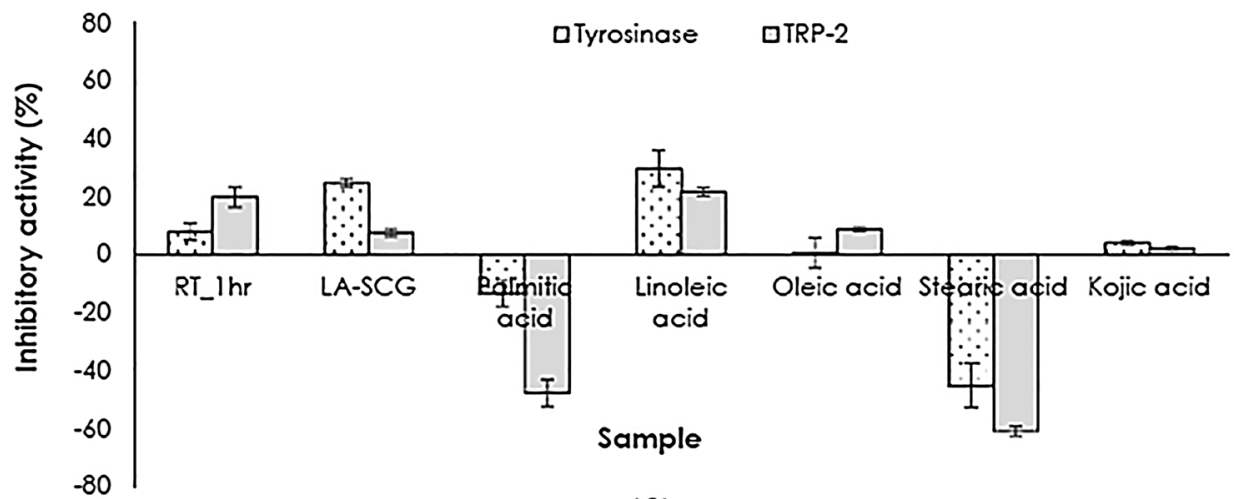

(C)

Fig. 3 Safety (a), and activities against melanogenesis (b), tyrosinase and TRP-2 (c) of SCG oils in B16F10 melanoma cells

\section{Tyrosinase and TRP-2 inhibitory effects}

Tyrosinase and TRP-2 cocontribute to melanogenesis in different steps of the pathway. Tyrosinase catalyzes tyrosine into dopa and further changes dopa into dopaquinone, the starting material of dopachrome. This is a critical rate-limiting step of melanin production. TRP-2 later catalyzes dopachrome into 5,6-dihydroxyindole2-carboxylic acid (DHICA), which will be further polymerized into eumelanins $[41,42]$. Thus, inhibitory effects against these melanogenesis enzymes will prevent skin dullness in several steps of melanogenesis and boost the skin lightening efficacy.

SCG oils significantly inhibited tyrosinase better than kojic and oleic acids $(p<0.01)$, as shown in Fig. 3c, in contrast to stearic and palmitic acids. Modification into LA-SCG oil clearly enhanced the inhibitory activity. Of these, LA-SCG oil was comparable to linoleic acid $(p=0.347)$. Moreover, the effective antityrosinase dose of this sample was 9.06-fold lower than its $\mathrm{IC}_{50}$, referring to its wide range of concentrations. SCG oils additionally 
inhibited TRP-2. Linoleic acid was shown to be the strongest TRP-2 inhibitor but was comparable to the unmodified SCG oil ( $p=0.690)$. Although LA-SCG oil inhibited TRP-2 less than the unmodified oil and linoleic and oleic acids, it was clearly more potent than kojic acid. Identical to promoting melanin production and tyrosinase activity, stearic and palmitic acids clearly promoted TRP-2 activity. The effective doses against TRP-2 of the unmodified and modified SCG oils were 9.15- and 9.06fold lower than its $\mathrm{IC}_{50}$.

Linoleic acid, the major fatty acid of SCG oils, was more specific to tyrosinase than TRP-2, which is consistent with the previous findings that linoleic acid potently degrades tyrosinase in the ubiquitin-proteasome pathway $[43,44]$. SCG oils were therefore confirmed to be more specific to tyrosinase, the critical rate-limiting step of melanogenesis, than TRP-2. Despite the more potent activity of linoleic acid against the enzymes in melanin production, the cellular melanin content was less suppressed with linoleic acid (Fig. 3b). LA-SCG oil should suppress melanogenesis in different steps of biosynthesis in addition to its inhibitory action against tyrosinase and TRP-2, that is, activity against (i) phenylalanine hydroxylase (PAH), which is the enzyme catalyzing phenylalanine into tyrosine and (ii) tyrosinase hydroxylase isoform I (THI), which accumulates with tyrosinase transforming tyrosine into dopa. Inhibition against these 2 enzymes resulted in a low amount of the starting material in melanogenesis [45], thus downregulating melanin production accordingly. Therefore, LA-SCG oil, the strongest antimelanogenesis sample in this study, not only inhibited tyrosinase and TRP-2 but may also possess inhibitory effects against PAH and THI. This is positively related to strong activity against melanin production and should be potent in in vivo skin hyperpigmentation treatment.

In regard to the skin lightening efficacy, an important sign of skin aging [24], of the SCG oils, their potential to be additionally used for antiaging was further explored in NHF.

\section{Safety and activity in NHF Safety assessment}

SCG oils were shown to be safe toward NHF at the same concentration range as that observed in B16F10 melanoma, similar to those of the standard fatty acids and ascorbic acid (Fig. 4a). The $\mathrm{IC}_{50}$ values of the unmodified and modified oils were calculated to be 0.8206 and $1.5672 \mathrm{mg} / \mathrm{mL}$, respectively. In addition, those of palmitic, linoleic, oleic and stearic acids and ascorbic acids were $0.2448,0.0687,0.0657$ and 0.1069 , and $1.0726 \mathrm{mg} /$ $\mathrm{mL}$, respectively. The maximum safe concentration of $0.01 \mathrm{mg} / \mathrm{mL}$ was thereafter examined for cellular activities.

\section{Cellular antioxidant activity}

NHF apoptosis was induced by $\mathrm{H}_{2} \mathrm{O}_{2}$-cellular oxidative stress [46], which reduced the viability of cells to $75.18 \pm 0.09 \%$. The cellular healing efficacy of SCG oils and the standards following oxidative stress were comparable (Fig. 4b). The antioxidant activity of SCG oils was ruled by their UFA constituents particularly linoleic acid, which was proven to have antioxidant activities by several in vitro and cellular assays [29, 47]. Meanwhile, those of the SFAs are moderate. Thus, the cellular antioxidant activity of SCG oils highlights their potency in combating aging and the dullness of skin [48].

\section{Cellular collagen production}

The ability of SCG oils to promote cellular collagen production was assessed by a histological procedure using the Sirius Red method specifically for collagen types I and III [22], which are the major components of the extracellular matrix (ECM) responsible for skin elasticity [49].

LA-SCG oil enhanced cellular collagen production in a potency comparable with those of linoleic and oleic acids and remarkably better than that of ascorbic acid $(p<0.01)$. Unmodified SCG oil similarly boosted collagen production with ascorbic acid (Fig. 4c). It should be noted that fatty acids enhance collagen production because they are components of skin cells and necessary for skin proliferation [50, 51]. Ascorbic acid was used as the benchmark standard in this study because it is a cofactor of prolyl and lysyl hydroxylase, the compulsory enzymes for collagen cross-linking and stabilizing procollagen messenger RNA (mRNA). Ascorbic acid additionally activates the gene expression of collagen and MMP tissue inhibitor synthesis [52], stimulating the cell matrix and mineralization at the same time. Longchain fatty acids (C-16 upwards) are necessary micronutrients for skin' tissue growth, particularly UFAs [50]. UFAs stimulate the proliferation of skin cells by several actions, including cellular antioxidant activity [53]. Of these, linoleic acid was reported to have a collagen production stimulating efficacy that was better than oleic acid $[54,55]$. Linoleic acid escalates mRNA expression in fibroblasts during the synthesis of collagen types I and III together with an induction of transforming growth factor- $\beta$ (TGF- $ß$ ). In addition, linoleic acid was proven to be better in TGF- 31 induction than TGF- 33 , while oleic acid was better in TGF- 33 induction than TGF- 31 [21]. Moreover, UFAs are able to act as a ligand for peroxisome proliferator-activated receptors (PPARs), important transcription factors of skin, and further promote the growth and proliferation of skin cells [56]. Linoleic and oleic acids strongly complex with PPARs, enhancing cellular collagen production accordingly [57]. In addition, UFAs stimulate collagen production by their inhibitory 


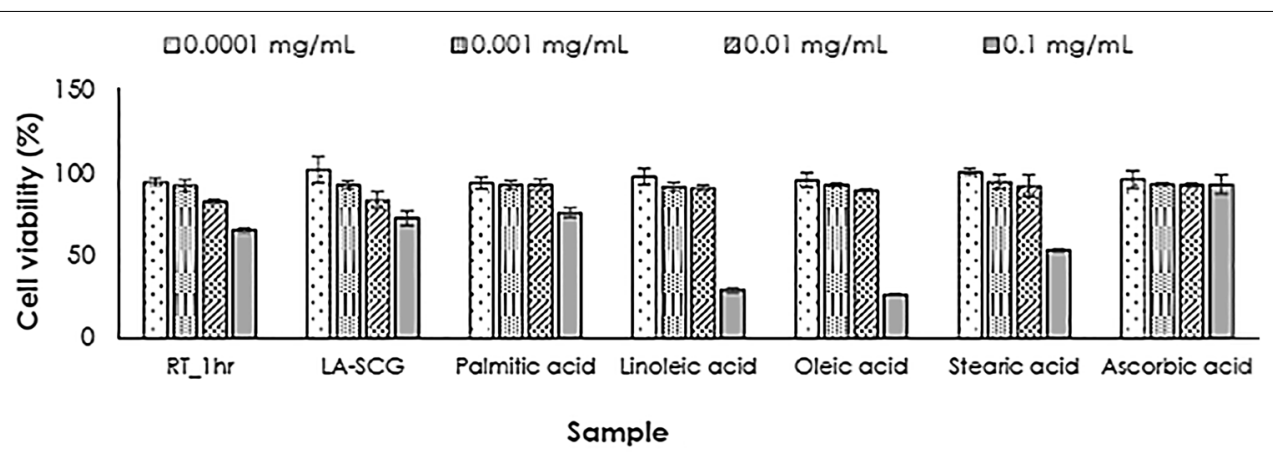

(A)

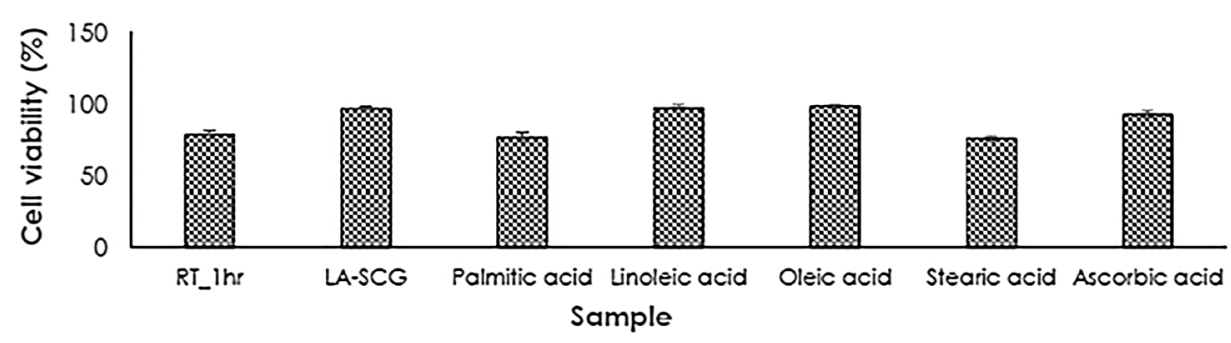

(B)

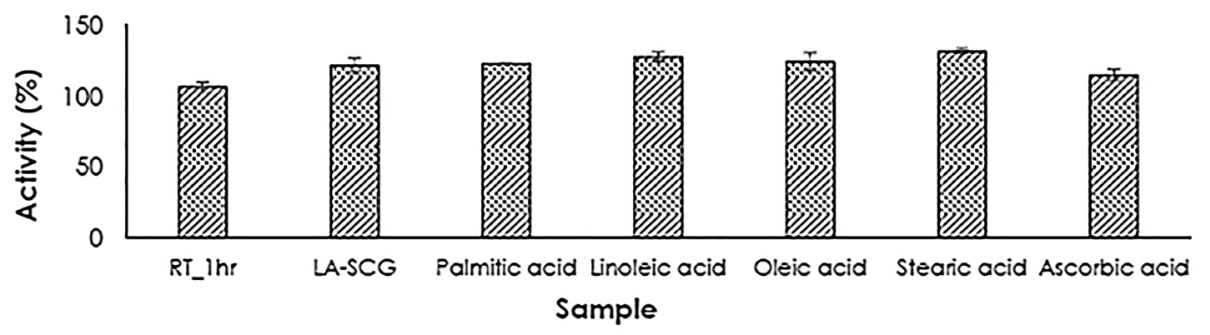

(C)



(D)

Fig. 4 Safety (a) and antioxidant (b), collagen stimulating (c) and MMP-2 inhibitory (d) activities of SCG oils in NHF cells

activities against cyclooxygenase-2 (COX-2) and mRNA expression of MMP-2 [58].

\section{Inhibitory effect against MMP-2}

MMPs are zinc-dependent endopeptidases that degrade ECM enzymes [59]. Those compulsory for skin are differentiated into 6 groups, i.e., collagenase (MMP-1, MMP-8, MMP-13 and MMP-18), gelatinase (MMP-2) and elastase (MMP-9 and MMP-12). MMP-2 is a type I, II, III and IV, elastin and fibronectin degradation enzyme that results in all signs of skin aging, including wrinkling and sagging [60]. Fatty acids especially those with carbon 
numbers greater than 18 and at least 1 double bound, exhibit inhibitory effects against MMPs [50]. In search of antiaging ingredients, especially those containing fatty acids as the active principles, the activity against MMP-2 has been more widely examined [20] than that of MMP-1 as those of fatty acids are insensible or not active against collagenase or MMP-1 [51].

LA-SCG oil posed a remarkable inhibitory effect against MMP-2 that was comparable to that of linoleic acid $(p>0.05)$ and significantly more potent than those of oleic acid and ascorbic acid $(p<0.001)$, as depicted in Fig. 4d. In contrast, SFAs and unmodified oil increased the enzyme activity due to its SFAs content (palmitic and stearic acids of $47.98 \%$ ). The inhibitory effect of UFAs is contributed to the antioxidant activity. Linoleic acid suppresses MMP-2 mRNA expression, MMP-2 proteolytic activity and vascular endothelial factor [61]. Oleic acid not only diminishes MMP-2 mRNA expression [57] but also its carboxylic acid moiety complexes with the metal center (zinc) of the enzyme molecule, and the alkyl chain additionally chelates with hydrophobic sites of the enzyme (fibronectin type II-like domains) [62]. The MMP-2 inhibitory mechanism of UFAs is therefore a direct interaction with the enzyme molecule. Ascorbic acid downregulates the transcription process of MMP-2 expression and thereafter suppresses reactive oxygen species-mediated activation of MMP prior to ECM degradation [63]. The activity of ascorbic acid against MMP-2 is therefore weaker than that of UFAs. Thus, plant oil with a high proportion of UFAs or a high UFA/SFA ratio is potent against MMP-2.

\section{Conclusion}

SCG have been proven to be a valuable source of specialty materials for cosmetics. The preparation of LA-SCG oil by cost-effective processes and feasible scaling-up is presented. LA-SCG oil (77.20\%) with a high UFA/SFA ratio (33.12) was confirmed to have physicochemical properties applicable for cosmetics. LA-SCG oil is safe and remarkably inhibits cellular melanin production, which was proven to have inhibitory effect against tyrosinase and TRP-2. In addition, the cellular antioxidant activity of LA-SCG oil is confirmed to be potent, as well as its collagen stimulating and MMP-2 inhibitory activities. This LA-SCG oil is highlighted as a promising specialty material for skin brightening and skin wrinkle reduction/ skin elasticity improvement products. Derivatization of coffee products for new industry uses, with high commercial value as a cosmetic active positively impacts the value chain of coffee and fits consumers' expectations of sustainable/natural cosmetics.

\section{Abbreviations}

AV: Acid value; CAMP: Cyclic adenosine monophosphate; Cl: Confidence intervals; COX-2: Cyclooxygenase-2; DHICA: 5,6-Dihydroxyindole-2-carboxylic acid; DMEM: Dulbecco's modified Eagle's medium; ECM: Extracellular matrix; EDTA: Ethylenediaminetetraacetic acid; EtOH: Ethanol; FAME: Fatty acid methyl esters; FBS: Fetal bovine serum; F_L: Supernatant of the frozen oil; F_S: Crystal of the frozen oil; GC/MS: Gas chromatography/mass spectrophotometry; IC50: Inhibitory concentration at 50\%; IV: Iodine value; LA-SCG: Linoleic acid-rich SCG oil; MeOH: Methanol; MMP: Matrix metalloproteinase; mRNA: Messenger RNA; NHF: Normal human dermal fibroblast; PAH: Phenylalanine hydroxylase; PBS: Phosphate buffer saline; PPAR: Peroxisome proliferator-activated receptor; PV: Peroxide value; RIPA: Radio immunoprecipitation assay; SDS-PAGE: Sodium dodecyl sulfate polyacrylamide gel electrophoresis; SCG: Spent coffee grounds; SEM: Standard error of the mean; SFA: Saturated fatty acid; SRB: Sulforhodamine B; SV: Saponification value; THI:Tyrosinase hydroxylase isoform I; TGF-ß: Transforming growth factor-ß; TRP-2: Tyrosinase related-protein-2; UFA: Unsaturated fatty acid; USV: Unsaponification value.

\section{Acknowledgements}

This research was financially supported by the Agricultural Research Development Agency of Thailand for fiscal year 2018 with the Grant No. CRP6105022110. The Quality Coffee Products Company Limited, Chachoengsao, Thailand, is acknowledged for spent coffee grounds. The authors acknowledge Mae Fah Luang University upon supports per the manuscript preparation and the reviewers on their valuable suggestions that make the article more comprehensive.

\section{Authors' contributions}

MK contributed to project planning, designed the study, cocontributed in cellular activities, data analysis and drafting of the manuscript. NL contributed to coffee oil preparations and analysis of the oils in terms of physicochemical properties and fatty acid profiles. PC had served in all parts of cellular activity assessment. All the authors have read and approved the final manuscript.

\section{Funding}

This research was financially supported by the Agricultural Research Development Agency of Thailand for fiscal year 2018 with the Grant No. CRP6105022110.

\section{Availability of data and materials}

Not applicable.

\section{Declarations}

Ethics approval and consent to participate

Not applicable.

Consent for publication

Not applicable.

Competing interests

The authors declared that there are no competing interests.

\section{Author details}

${ }^{1}$ School of Cosmetic Science, Mae Fah Luang University, Chiang Rai 57100, Thailand. ${ }^{2}$ Phytocosmetics and Cosmeceuticals Research Group, Mae Fah Luang University, Chiang Rai 57100, Thailand.

Received: 3 June 2021 Accepted: 25 August 2021

Published online: 27 October 2021

References

1. Thailand Ministry of Agriculture and Cooperatives, Department of Agriculture. 2017. http://www.agriman.doae.go.th/home/news/2562/33-34. pdf. Accessed 15 Oct 2019.

2. Hoseni M, Cocco S, Casucci C, Cardelli V, Corti G. Coffee by products derived resources. A review. Biomass Bioener. 2021;148: 106009. https:// doi.org/10.1016/j.biombioe.2021.106009. 
3. López-Linares JC, García-Cubero MT, Coca M, Lucas S. A biorefinery approach for the valorization of spent coffee grounds to product antioxidant compounds and biobutanol. Biomass Bioener. 2021;147: 106026. https://doi.org/10.1016/j.biombioe.2021.106026.

4. Kanlayavattanakul $\mathrm{M}$, Lourith $\mathrm{N}$. Therapeutic agents and herbs in topical application for acne treatment. Int J Cosmet Sci. 2011;33:289-97.

5. Kanlayavattanakul M, Lourith N. An update on cutaneous aging treatment using herbs. J Cosmet Laser Ther. 2015;17:343-52.

6. Lourith N, Kanlayavattanakul M. Hair loss and herbs for treatment. J Cosmet Dermatol. 2013;12:210-22.

7. Oliveira LS, Franca AS, Mendonça JCF, Barros-Júnior MC. Proximate composition and fatty acids profiles of green and roasted defective coffee beans. LWT. 2006:39:235-9.

8. Massaya J, Pereira AP, Mills-Lamptey B, Benjamin J, Chuck CJ. Conceptualization of a spent coffee grounds biorefinery: a review of existing valorization approaches. Food Bioprod Proc. 2019;118:149-66.

9. Al-Hamamre Z, Foerster S, Hartmann F, Kröger M, Kaltschmitt M. Oil extracted from spent coffee grounds as a renewable source for fatty acid methyl ester manufacturing. Fuel. 2012;96:70-6.

10. Moncada JB, Aristizábal MV, Cardona CAA. Design strategies for sustainable biorefineries. Biochem Eng J. 2016;116:122-34.

11. Santana-Méridas O, González-Coloma A, Sánchez-Vioque R. Agricultural residues as a source of bioactive natural products. Phytochem Rev. 2012;11:447-66.

12. Tiedtke J. Information requirements for botanical cosmetic ingredients. Cosmet Sci Technol. 2006;1:15-21.

13. Lourith N, Kanlayavattanakul M, Mongkonpaibool K, Butsaratrakool T, Chinmuang T. Rambutan seed as a new promising unconventional source of specialty fat for cosmetics. Ind Crop Prod. 2016;83:149-54.

14. Lourith N, Kanlayavattanakul M, Sucontphunt A, Ondee T. Para rubber seed oil: new promising unconventional oil for cosmetics. J Oleo Sci. 2014:63:709-16

15. Salimon J, Abdullah BM, Salih N. Selectively increasing of polyunsaturated (18:2) and monounsaturated (18:1) fatty acids in Jatropha curcas seed oil by crystallization using D-optimal design. Chem Central J. 2012;6:65. https://doi.org/10.1186/1752-153X-6-65.

16. Hayes DG, Bengtsson $Y C$, van Alstine JM, Setterwall F. Urea complexation for the rapid, ecological responsible fractionation of fatty acid from seed oil. J Am Oil Chem Soc. 1998;75:1403-9.

17. AOCS. Official methods and recommended practice of the AOCS. 5th ed. Illinois: AOCS; 1997.

18. Kanlayavattanakul M, Chongnativisit W, Chaikul P, Lourith N. Phenolic-rich pomegranate peel extract: in vitro, cellular, and in vivo activities for skin hyperpigmentation treatment. Planta Med. 2020;86:749-59.

19. Hu DN. Methodology for evaluation of melanin content and production of pigment cells in vitro. Photochem Photobiol. 2008;84:645-9.

20. Lourith N, Kanlayavattanakul M, Chaikul P, Chansriniyom C, Bunwatcharaphansakun P. In vitro and cellular activities of the selected fruits residues for skin aging treatment. An Acad Bras Ciênc. 2017:89:577-89.

21. Beam J, Botta A, Ye J, Soliman H, Matier BJ, Forrest M, MacLeod KM, Ghosh S. Excess linoleic acid increases collagen I/III ratio and "stiffens" the heart muscle following high fat diets. J Biol Chem. 2015;290:23371-84.

22. Tullberg-Reinert $\mathrm{H}$, Jundt $\mathrm{G}$. In situ measurement of collagen synthesis by human bone cells with a Sirius Red-based colorimetric microassay: effects of transforming growth factor ß2and ascorbic acid 2-phosphate. Histochem Cell Biol. 1999;112:271-6.

23. Ribeiro H, Marto J, Raposo S, Agapito M, Isaac V, Chiari BG, Lisboa PF, Paiva A, Barreiros S, Simões P. From coffee industry waste materials to skinfriendly products with improved skin fat levels. Eur J Lipid Sci Technol. 2013:115:330-6.

24. Kanlayavattanakul M, Lourith N. Plants and natural products for the treatment of skin hyperpigmentation - a review. Planta Med. 2018;84:988-1006.

25. Kovalcik A, Obruca S, Marova I. Valorization of spent coffee grounds: a review. Food Bioprod Proc. 2018;110:104-19.

26. Liu SX, Mamidipally PK. Quality comparison of rice bran oil extracted with d-limonene and hexane. Cereal Chem. 2005;82:209-15.

27. Freitas SP, Monteiro PL, Lago RC. Extração do óleo da borra de café solúvel com etanol commercial. Simp Pesqui Cafés Brasil. 2000;5:740-3.
28. Ahangari B, Sargolzaei J. Extraction of lipids from spent coffee grounds using organic solvents and supercritical carbon dioxide. J Food Proc Presev. 2013:37:1014-21.

29. Chaikul P, Lourith N, Kanlayavattanakul M. Antimelanogenesis and cellular antioxidant activities of rubber (Hevea brasiliensis) seed oil for cosmetics. Ind Crop Prod. 2017;108:56-62.

30. Chaikul P, Sripisut T, Chanpirom S, Sathirachawan K, Ditthawuthikul N. Melanogenesis inhibitory and antioxidant effects of Camellia oleifera seed oil. Adv Pharm Bull. 2017:7:473-7.

31. Abedi E, Sahari MA. Long-chain polyunsaturated fatty acid sources and evaluation of their nutritional and functional properties. Food Sci Nutri. 2014:2:443-63

32. Mata TM, Martins AA, Caetano NS. Bio-refinery approach for spent coffee grounds valorization. Biores Technol. 2018;247:1077-84.

33. Kissil GWM, Koven WM. Preparation of oils, enhanced in highly unsaturated fatty acid (HUFA) content by low temperature crystallization separation for rotifer (Brachionus plicatilis) enrichment. Aquaculture. 1990;88:69-74

34. Lyons JM, Asmundson CM. Solidification of unsaturated/saturated fatty acid mixtures and its relationship to chilling sensitivity in plants. J Am Oil Chem Soc. 1965;42:1056-8.

35. Anger P, Destaillats F, Galvez JMG. Conjugated linolenic acids and methods for commercial preparation and purification. US Patent. US 2006/0281814A1, 2006

36. Yang T-S, Liu T-T. Optimization of production of conjugated linoleic acid from soybean oil. J Agric Food Chem. 2004;52:5079-84.

37. Hu F. Theophylline and melanocyte-stimulating hormone effects on gamma-glutamyl transpeptidase and DOPA reactions in cultured melanoma cells. J Invest Dermatol. 1982:79:57-62.

38. Battaini G, Monzani E, Casella L, Santagostini L, Pagliarin R. Inhibition of the catecholase activity of biomimetic dinuclear copper complexes by kojic acid. J Biol Inorg Chem. 2000;5:262-8.

39. Ando H, Funasaka Y, Oka M, Ohashi A, Furumura M, Matsunaga J, Matsunaga N, Hearing VJ, Ichihashi M. Possible involvement of proteolytic degradation of tyrosinase in the regulatory effect of fatty acids on melanogenesis. J Lipid Res. 1999:40:1312-6.

40. Ando H, Ryu A, Hashimoto A, Oka M, Ichihashi M. Linoleic acid and a-linolenic acid lightens ultraviolet-induced hyperpigmentation of the skin. Arch Dermatol Res. 1998;290:375-81.

41. Park HY, Kosmadaki M, Yaar M, Gilchrest BA. Cellular mechanisms regulating human melanogenesis. Cell Mol Life Sci. 2009;66:1493-506.

42. Schallreuter KU, Kothari S, Chavan B, Spencer JD, Regulation of melanogenesis-controversies and new concepts. Exp Dermatol. 2008:17:395-404

43. Lam RYY, Lin ZX, Sviderskaya E, Cheng CHK. Application of a combined sulphorhodamine $B$ and melanin assay to the evaluation of Chinese medicines and their constituent compounds for hyperpigmentation treatment. J Ethnopharmacol. 2010;132:274-9.

44. Maeda K, Naitou T, Umishio K, Fukuhara T, Motoyama A. A novel melanin inhibitor: hydroperoxy traxatane-type triterpene from flowers of Arnica montana. Biol Pharm Bull. 2007:30:873-9.

45. Gillbro JM, Olsson MJ. The melanogenesis and mechanisms of skinlightening agents_-existing and new approaches. Int J Cosmet Sci. 2011;33:210-21.

46. Whittemore ER, Loo DT, Watt JA, Cotmans CW. A detailed analysis of hydrogen peroxide-induced cell death in primary neuronal culture. Neurosci. 1995;67:921-35.

47. Henry GE, Momin RA, Nair MG, Dewitt DL. Antioxidant and cyclooxygenase activities of fatty acids found in food. J Agric Food Chem. 2002:50:2231-4.

48. Darr D, Fridovich I. Free radical in cutaneous biology. J Invest Dermatol. 1994:102:671-5.

49. Lourith N, Kanlayavattanakul M. Biopolymeric agents for skin wrinkle treatment. J Cosmet Laser Ther. 2016:18:301-10.

50. Huet E, Cauchard J-H, Berton A, Roninet A, Decarme M, Hornebeck W, Bellon G. Inhibition of plasmid-mediated prostromelysin-1 activation by interaction of long chain unsaturated fatty acids with kringle 5. Biochem Pharmacol. 2004:67:643-54. 
51. Kim EJ, Jin X-J, Kim YK, Oh IK, Kim JE, Park C-H, Chung JH. UV decreases the synthesis of free fatty acids and triglycerides in the epidermis of human skin in vivo, contributing to development of skin photoaging. J Dermatol Sci. 2010;57:19-26.

52. Al-Niaimi F, Chiang NYZ. Topical vitamin C and the skin: mechanisms of action and clinical applications. J Clin Aesthet Dermatol. 2017;10:14-7.

53. Jia Y, Gan Y, He C, Chen Z, Zhou C. The mechanism of skin lipids influencing skin status. J Dermatol Sci. 2018;89:112-9.

54. Jia Y, Turek JJ. Altered NF-kB gene expression and collagen formation induced by polyunsaturated fatty acids. J Nutr Biochem. 2005;16:500-6.

55. Rodrigues H, Vinolo MAR, Sato FT, Magdalon J, Kuhl CMC, Yamagata AS, Pessoa AFM, Malheiros G, dos Santos MF, Lima C, Farsky SH, Camara NOS, Williner MR, Bernal CA, Calder PC, Curl R. Oral administration of linoleic acid induces new vessel formation and improves skin wound healing in diabetic rats. PLoS ONE. 2016. https://doi.org/10.1371/journal.phone. 0165115.

56. Sertzing P, Seifert M, Tilgen W, Reichrath J. Peroxisome proliferator-activated receptors (PPARs) and the human skin: importance of PPARs in skin physiology and dermatologic diseases. Am J Clin Dermatol. 2008;9:15-31.

57. Still K, Grabowski P, Mackie I, Perry M, Bishop N. The peroxisome proliferation activator receptor alpha/delta agonists linoleic acid and benzafibrate upregulate osteoblast differentiation and induce periosteal bone formation in vivo. Calcif Tissue Int. 2008;83:285-95.

58. Cardoso CR, Favoreto S Jr, Oliveira LL, Vancim JO, Barban GB, Ferraz DB, Silva JS. Oleic acid modulation of the immune response in wound healing: a new approach for skin repair. Immunobiol. 2011;216:409-15.
59. Woessner JF Jr. Matrix metalloproteinases and their inhibitors in connective tissue remodeling. FASEB J. 1991;5:2145-54.

60. Visse R, Nagase H. Matrix metalloproteinases and tissue Inhibitors of metalloproteinases: structure, function, and biochemistry. Circ Res. 2003;92:827-39.

61. Miyake JA, Benadiba M, Colquhoun A. Gamma-linolenic acid inhibits both tumour cell cycle progression and angiogenesis in the orthotopic C6 glioma model through changes in VEGF, Flt1, ERK1/2, MMP2, cyclin D1, pRb, p53 and p27 protein expression. Lipids Health Dis. 2009. https:// doi.org/10.1186/1476-511X-8-8.

62. Emonard H, Marcq V, Mirand C, Hornebeck W. Inhibition of gelatinase A by oleic acid. Ann NY Acad Sci. 1999;878:647-79.

63. Orbe J, Rodríguez JA, Arias R, Belzunce M, Nespereira B, Pérez-Ilzarbe M, Roncal C, Páramo JA. Antioxidant vitamins increase the collagen content and reduce MMP-1 in a porcine model of atherosclerosis: implications for plaque stabilization. Atherosclerosis. 2003;167:45-53.

\section{Publisher's Note}

Springer Nature remains neutral with regard to jurisdictional claims in published maps and institutional affiliations.

\section{Submit your manuscript to a SpringerOpen ${ }^{\circ}$ journal and benefit from:}

- Convenient online submission

- Rigorous peer review

- Open access: articles freely available online

- High visibility within the field

- Retaining the copyright to your article

Submit your next manuscript at $>$ springeropen.com 